\title{
Transferencia de blastocisto: ¿Mejorando las tasas de implantación y embarazo?
}

\author{
José Ignacio Madero Cervera. M.D.*; Eduardo Sanz Ramírez. BSc; Luz Mábel Avila Portillo MSc.; Magaly Escobar MSc.; \\ Jesús Alberto Ruiz Ruiz M.D.
}

RESUMEN: Las tasas de embarazo en la fertilización in vitro, transfiriendo en día 2 ó 3 se encuentran aún alrededor del $22 \%$, debiéndose transferir tres o más embriones, lo que da en promedio una tasa de implantación de un $10 \%$ por embrión transferido. Actualmente se trata de llegar hasta etapas tardías del desarrollo embrional in vitro, en un intento por acercarnos al modelo natural en el cual los embriones alcanzan el útero en estado de blastocisto, con el fin de mejorar las tasas de implantación y embarazo. Para tal efecto se han desarrollado nuevos medios de cultivo, cuya composición se basa en estudios de fisiología embrional y del medio natural en el cual se desarrolla el embrión (inicialmente en la trompa y posteriormente en el útero) generando el concepto de "cultivo de embriones en medios secuenciales" donde la etapa inicial de desarrollo se haría en medios libres de glucosa y a partir del día 3 (estado de 8 células) se cambiarían a medios con glucosa lo que, según los estudios publicados hasta la fecha, mejoraría substancialmente el número de embriones que alcanzarían el estado de blastocisto (cerea del $60 \%$ ) con altas tasas de implantación y, por consiguiente, la necesidad de transferir menor número de embriones por paciente disminuyendo de manera considerable la posibilidad de embarazo múltiple.

PALABRAS CLAVES: Blastocisto, desarrollo embrionario, medios de cultivo, cocultivos.

SUMMARY: The pregnancy rates in IVF-ET, after transfer in days 2 or 3 remain lower, near the $22 \%$ with 3 or more embryos transfered and with implantations rates per embryo transfer of $10 \%$. At present the study is trying to reach the late stages of the embryo development in vitro, on purpose to imitate the natural model in which the embryos arrives to the uther in blastocyst stage, with the goal of increasing implantation and pregnancy rates. For this effect, new culture mediums have been developed, whose composicion are based on embryo fisiology studies and in the research about the composition of the natural medium in which the embryo developes ( inicially in the fallopian tube and later in the uterus), arising the concept of "embryo culture in secuencial mediums", where the inicial stage of embryo development will be done in glucosa free mediums and after the day 3 ( 8 cells stage) it will be change to glucosa mediums, and with this, as the recently publications state, it would increse the number of embryos that woul reach the blastocyst stage ( near $60 \%$ ) with high implantation and lower number of embryo transfer per patient decreasing the possibility of multiply pregnancy.

KEY WORDS: Blastocyst, culture mediums, embryonic development, co-culture.

Luego de 20 años del nacimiento de la primera niña utilizando la fertilización in vitro, las tasas de embarazo y de bebé en casa, son aún bajas, con un porcentaje de gestación por ciclo transferido que oscila entre el $20-30 \%$ en ciclos de FIV, y alrededor del $50 \%$ cuando las pacientes reciben donación de ovocitos (1-2). El éxito en estos procedimientos depende de una adecuada sincronización entre un endometrio receptivo (ventana de implantación) y el momento en el cual el embrión alcance el estado de blastocisto, para que se produzca la adhesión, invasión y gestación.

Generalmente en los programas de in vitro, las transferencias de embriones se realizan en el día dos (4 células), o en el día tres ( 8 células) postfertilización. Aquí es importante recordar que in vivo las etapas de clivaje anteriores a

Director Científico Medifértil. Programa de Medicina Reproductiva. la aparición del blastocisto, se realizan en la trompa de Falopio y no en el útero, lo que de por sí puede dar como resultado una disminución de las tasas de embarazo al transferir directamente al útero embriones en estados de desarrollo propios de la trompa; esto se ha demostrado en otras especies de mamíferos al obtenerse mejores tasas de embarazo transfiriendo embriones al útero en estado de postcompactación o en blastocisto. (3). Los datos actuales al transferir en humanos mórula cavitada y/o blastocisto en día 4 ó 5 del desarrollo, muestran una duplicación en las tasas de implantación al compararlas con transferencias de embriones en estados anteriores de clivaje, lo cual confirma la hipótesis de que al transferir embriones en etapas tardías (cercano al modelo natural) se incrementarían las tasas de implantación y embarazo por embrión transferido: $60 \%$. (4-6).

Algunas de las ventajas de cultivar y transferir blastocistos serían:

1. Sincronización con el endometrio, aumentando las 
tasas de implantación por embrión transferido y evitando la transferencia de múltiples embriones.

2. Determinación de la viabilidad del embrión antes de la transferencia, identificando los embriones con poco potencial de desarrollo que se manifiestan por crecimiento lento o su degeneración en el cultivo, y la posibilidad de utilizar pruebas no invasivas que detectan el potencial de desarrollo del embrión dentro del grupo que se va a transferir. (7).

3. Aumenta el tiempo entre la biopsia del embrión en etapa de clivaje y su transferencia (8).

4. Permite realizar la biopsia de trofectodermo, que representa la forma de diagnóstico genético más temprano de material no embrionario.

El cultivo de blastocisto no se ha utilizado de rutina, en parte, por la incapacidad de mantener embriones en cultivo por más de dos días sin que se comprometa su viabilidad; es importante diferenciar entre la capacidad de un medio para contribuir al desarrollo in vitro hasta blastocisto, de su capacidad para hacerlo viable. Los estudios iniciales mostraron una tasa de obtención de blastocistos de un $42 \%$, utilizando medios de cultivo suplementados con suero materno al 10\% (9). Cuando se sustituyó el suero materno por albúmina sérica bovina y se disminuyó el volumen de medio de cultivo, se incrementó a un 59\% la obtención de blastocistos, pero con unas tasas de embarazo similares a las obtenidas al transferir en el día 2 ó 3. (10). Al utilizar sistemas de co-cultivos con células Vero se han obtenido tasas de desarrollo hasta blastocisto similares, pero en los estudios prospectivos, randomizados no se han demostrado buenos resultados. (11-12).

No siempre que obtenemos blastocistos persiste una buena tasa de implantación y de nacidos vivos, lo cual indica que no todos los blastocistos son viables. De otro lado, diferentes medios de cultivo que alcanzan iguales porcentajes de blastocistos, tienen diferentes tasas de embarazo (13). Igualmente, no todos los embriones en pronúcleos alcanzarán la etapa de blastocistos ya que un número importante serán anormales; se ha determinado que aproximadamente el $25 \%$ de los ovocitos son aneuploides y que éste porcentaje se aumenta con la edad materna. (1415). Otra ventaja del cultivo hasta blastocisto sería la posibilidad de descartar los pocos embriones anormales que puedan progresar a blastocisto, utilizando la biopsia de trofectodemo. Entre los factores que contribuyen al desarrollo anomal del embrión están la insuficiencia de los productos codificados genéticamente y almacenados en el ovocito y una falla en la activación del genoma del embrión (16). Podemos considerar el cultivo in vitro de embriones hasta blastocisto, como parte de una selección natural durante su desarrollo, lo cual hace del embrión que llega hasta este estadío el de mayor potencial de desarrollo.

Actualmente existe un gran desarrollo en el campo de los medios de cultivo que nos brinda la posibilidad de poder alcanzar el estado de blastocisto en humanos con mejores resultados, teniendo además la posibilidad de utilizar medios sin sueros, ni co-cultivos con células somáticas.
Estos avances tecnológicos en el campo de los medios de cultivo se han dado merced a los conceptos de fisiología y desarrollo embrional basados en estudios del aparato reproductor femenino, logrando obtener medios que contribuyen al desarrollo del embrión en ésta etapa de preimplantación tan dinámica. Así se ha podido llegar a establecer que la composición de éstos medios debe cambiar de acuerdo a las etapas de crecimiento del embrión.

\section{Fisiología embrionaria}

En el modelo natural la fertilización ocurre a nivel de la trompa de Falopio (17), y el zigoto punto de partida de la fertilización, tiene poca similitud con el blastocisto, punto final del proceso de preimplantación. Es por eso que dividimos el cultivo de embriones en dos etapas: una etapa I de clivaje en la cual la tasa respiratoria, de biosíntesis y el consumo de glucosa como fuente de energía son bajos y la etapa II o de post-compactación en la que se incrementan la capacidad respiratoria, la biosintesis y la utilización de glucosa. Cualquier alteración mínima en las vías de producción de energía por parte del embrión tendrá un efecto deletéreo en su desarrollo. Antes de la compactación se considera cada blastómera como una entidad independiente, con mecanismos reguladores sofísticados iguales a los de un organismo unicelular. La compactación posterior, representa la formación del primer epitelio de transporte del embrión, siendo capaz de regular su medio interno. Esta fase de tanta susceptibilidad del embrión coincide con la activación del genoma (18).

Otro factor que tiene gran influencia en el desarrollo embrionario es el volumen de medio utilizado, ya que se logran mejores resultados utilizando volúmenes reducidos : menos de $1 \mathrm{ml}$. Otro efecto benéfico se obtiene al reunir varios embriones en pequeños volúmenes ya que se aprovecha la producción de factores auto y paracrinos (Factor activador de plaquetas y Factor de crecimiento similar a la Insulina) por los embriones, mejorando su crecimiento. El cultivo en volúmenes grandes produciría un efecto de dilución de estos factores y lo que disminuye el número de células de la masa interna del blastocisto, al compararlo con embriones cultivados en volúmenes reducidos (19).

\section{Medios de cultivo}

Se han desarrollado medios adecuados para todas las etapas previas a la implantación divididos en simples como el medio de Earle's, el T6 y el HTF (Human Tubal Fluid) constituidos por soluciones salinas balanceadas con fuentes de energía como piruvato, lactato y glucosa, y los complejos como el Alfa-MEM y el Ham's F-10, para ser usados específicamente en cultivos de células somáticas in vitro. Usualmente se suplementan con suero materno o fetal. A pesar de tener grandes diferencias en cuanto a su composición tienen tasas de desarrollo embrionario y embarazos similares : no mayores de 20$30 \%$ por transferencia de múltiples embriones. Esto podria explicarse porque la transferencia de embriones es temprana. antes que diferencias importantes aparezcan. 
Los efectos negativos de la glucosa en el embrión en etapas iniciales del desarrollo (19-20) son contrarrestados parcialmente por el consumo que tienen las células del cumulus (muy activas metabólicamente) que rodean al ovocito y al embrión en sus etapas iniciales, con liberación de lactato y piruvato. Esto nos sugiere que in vivo el ovocito y el embrión están en un medio libre de glucosa lo que se ha confirmado con estudios de la composición de fluidos a nivel de la trompa: niveles bajos de glucosa y altos de piruvato cuando se está produciendo la captación de ovocitos y las etapas iniciales de la fertilización, y posteriormente cuando llega a la cavidad uterina se encuentran niveles elevados de glucosa y bajos de piruvato. Aunque la tendencia actual es que los medios de desarrollo en etapas tempranas no contengan glucosa, es importante recordar que el embrión hasta etapa de dos células, ya posee un mecanismo de transporte de glucosa, que en presencia de reguladores apropiados como los aminoácidos, no se altera el desarrollo embrional y que la glucosa tiene funciones importantes diferentes a la de fuente de energía : precursor anabólico y necesario para la síntesis de triacilgliceroles y fosfolípidos así como precursor de azúcares complejos como glicoproteínas y mucopolisacáridos. La glucosa es metabolizada por la vía de las pentosas generando moléculas de ribosa necesarias para la síntesis de ácidos nucleicos y el fosfato dinucleotido de nicotinamida reducido (NADPH) requerido para la biosíntesis de lípidos y otras moléculas complejas. El NADPH está presente en la reducción del glutatión intracelular, importante antioxidante para el embrión. La utilización de estos medios con o sin glucosa llevan al embrión hasta etapa de blastocisto pero lo que haría la diferencia sería la tasa de implantación, que está por definirse aunque estudios preliminares reportan resultados halagadores que bordean el $60 \%$. En cuanto a los aminoácidos esenciales y no esenciales, es evidente que con los grandes cambios del metabolismo energético del embrión, existe un aumento en los requerimientos de nitrógeno del embrión : la exposición por cinco minutos en un medio sin aminoácidos produce una alteración severa en el desarrollo del embrión, pues, al parecer, pierde su contenido de aminoácidos intracelulares al verterlos al medio que lo rodea produciendo un trauma intracelular; son por lo tanto reguladores del metabolismo energético, de la osmolaridad y sirven de buffer. Estos aminoácidos son metabolizados por el embrión liberando amonio el cual es embriotóxico, alterando el desarrollo en el cultivo reduciendo significativamente la viabilidad. Estudios en el ratón mostraron que produce alteraciones en el tubo neural y exencefalia (21), por lo que se desarrolló un método para transaminar el amonio en el medio de cultivo a glutamato adicionándole al medio a usar a las 48 horas, la enzima glutamato dehidrogenasa, el sustrato alfacetoglutarato y el cofactor NADH que convierten el amonio a glutamato (21). Esto produjo un incremento significativo en la viabilidad de los blastocistos, confirmando que la exposición continua de los embriones a estos factores estimula su desarrollo.
El quelante utilizado en los medios de cultivos es el EDTA, cuya función es secuestrar los cationes divalentes e inhibir la prematura utilización de glucólisis, previniendo el efecto Crabtree, que conduce a una detención en el desarrollo embrional. En la etapa de post-compactación el quelante tiene un efecto negativo: inhibe el desarrollo del blastocisto y su número de células (MCI). El embrión, por lo tanto, no debe estar expuesto a este quelante luego de alcanzar el estado de 8 células.

Un suplemento utilizado con el medio de cultivo es el suero, el cual es obtenido de un coágulo de sangre, a diferencia del líquido de la trompa que es secretado por el epitelio. El suero varía en su composición de acuerdo al día del ciclo menstrual, enfermedades, ayuno, dieta, lo cual hace difícil la evaluación de resultados siendo además un recargo en el trabajo del laboratorio de In vitro y potencial transmisor de enfermedades. En los cultivos de embriones de oveja, se demostraron efectos adversos : formación precoz de blastocele, secuestro de lípidos, alteración de la ultraestructura mitocondrial, alteraciones metabólicas y anomalías congénitas. Las razones de estos efectos no han sido dilucidadas, pero en los cultivos en humanos con transferencias en día 2 ó 3, puede que no se altere por no estar aúm presentes receptores para factores de crecimiento. De otro lado, es un quelante potencial de las sustancias embriotóxicas, actúa como buffer y protege así las etapas de clivaje. Contrario a lo que se creía, el suero no es necesario para el éxito del cultivo, y puede y debe ser reemplazado por una forma de albúmina sérica o una macromolécula como el hialuronato.

\section{Nuevos medios de cultivo}

Sí la idea es continuar el cultivo hasta blastocisto, lo que nos pondría mas cerca del modelo natural, los medios antes mencionados no son los adecuados, especialmente si son suplementados con suero. Actualmente contamos con dos tipos de medios : el P1, libre de glucosa para la primera etapa (día 0 a 3) y el Blastocyst Medium (hasta día 4 ó 5), de Irvine Scientific, el S1 y S2 de Scandinavian Scientific, el G1-G2 (medios de Gardner) todos con reportes de aproximadamente un $60 \%$ en promedio de obtención de blastocisto y una tasa de implantación, transfiriendo en promedio 2, 75 blastocistos, del 22 al $38 \%$ y con embarazo en curso del 37\% (23-24).

\section{Viabilidad embrionaria}

La viabilidad embrionaria es algo subjetivo y el parámetro más utilizado es la morfología. El desarrollo de métodos cuantitativos para valorar el potencial de desarrollo del embrión mejorará las tasas de embarazos en In vitro. La capacidad de predecir cuando un embrión tiene una mayor viabilidad en un cultivo, se asocia con la tasa y velocidad de clivaje (25). Las tasas de implantación y embarazo de mórulas y blastocistos procedentes de embriones de crecimiento lento son bajas, a diferencia de los procedentes de embriones de división rápida. Otro método para 
medir la viabilidad del embrión se está utilizando en ratones, cuantificando su metabolismo energético mediante formas no invasivas como la ultramicrofluorescencia utilizada para medir la captación de glucosa antes de ser transferidos, hallándose que los que llegaron a término fueron los que más glucosa captaron en el cultivo (7).

De otro lado, los embriones que tuvieron una excesiva producción de lactato, perdieron su control sobre el metabolismo energético y son poco viables. Cuando se transfirieron blastocistos con una adecuada actividad glicolítica, la tasa de desarrollo fetal en los ratones fue del $80 \%$, al compararlo con los blastocistos que mostraban una elevada tasa de actividad glucolítica que fue del 6\% (22).

\section{Conclusiones}

En ésta revisión se logran apreciar las ventajas del cultivo embrionario hasta la etapa de blastocisto, los resultados con diferentes medios de cultivo y sus tasas similares en fertilización, implantación y embarazo, cuando se utilizan co-cultivos y suero. La mejoría en eficiencia de la fertilización in-vitro en humanos, el aumento en la calidad embrionaria y el número de estos que llegan a blastocisto conducen a transferencias con un número menor de embriones para obtener un embarazo disminuyendo la tasa de gestación múltiple y por consiguiente mejorando la tasa de implantación por embrión transferido.

\section{BIBLIOGRAFIA}

1. Society for Assisted Reproductive Technology and The American Society for Reproductive Medicine. Assited Reproductive Technology in the United States and Canada: 1994 results generated from the American Society for Reproductive Medicine/ Society for Assisted Reproductive Technology Registry. Fertil Steril 1996; 66: 697.

2. Remohí J., Vidal A., Pellicer A. Oocyte donation in low responders to a conventional ovarian stimulation for in-vitro fertilization. Fertil Steril 1993; 59: 1208.

3. Bavister B.D. Culture of preimplantation embryos: facts and artifacts. Hum. Reprod. Update 1995; 1 : 91.

4. Scholtes M.C.W., Zeilmaker GH. A prospective, randomized study of embryo transfer results after 3 or 5 days of embryo culture in in vitro fertilization. Fertil Steril 1996; 65: 1245.

5. Buster JE., Bustillo M., Rodi LA. et al. Biologic and morphologic development of donated human ova by nonsurgical uterine lavage. Am. J. Obstet. Gynecol. 1985; 153: 211.

6. Carrillo AJ., Lane B., Pridham D. et al. Improved clinical outcomes for in vitro fertilization with delay of embryo transfer from 48 to 72 hours after oocyte retrieval: use of glucose-and phosphate-free media. Fertil Steril 1998; 69: 329.

7. Lane M., Gardner DK. Selection of viable mouse blastocyst prior to transfer using metabolic criterion. Human Reprod. 1975 , 1996; 11:197

8. Ménézo Y., Ben Khalifa M. Cytogenetic and cryobiology of human cocultured embryos: a 3 year experience. J. Assist. Reprod. Genet. 1995; 12:35.

9. Hardy K., Handyside AH., Winston R.M.L. The human blastocyst: cell number, death and allocation during late preimplantation development in vitro. Development. 1989; 107: 597 .

10. Hardy K., Hooper M.A.K., Handyside A.H. et al. Non-invasive measurement of glucose and pyruvate uptake by individual human oocites and preimplantation embryos. Hum. Reprod. 1989; 4: 188.

11. Van Blerkom J. Development of human embryos to the hatched blastocyst stages in the presence or absence of a monolayer of vero cells. Hum. Reprod. 1993; 8: 1525.

12. Sakkas D., Jaquenoud N., Leppens G., CampanaA. Comparison of results after in vitro fertilized human embryos are cultured in routine medium and in coculture on vero cells: a randomized study. Fertil Steril 1994; 61: 521.

13. Lane M., Gardner DK. Non-essential amino acids and glutamine decrese the time of the first three cleavage divisions and increase compaction of mouse zygotes in vitro. J. Assist. Reprod. Genet. 1997; 14: 398.
14. Van Blerkom J. Developmental failure in human reproduction associated with chromosomal abnormalities and cytoplasmic pathologies in meiotically mature ooytes. En Van Blerkom J. (Edit). The Biological Basis of early human reproductive failure. Oxford University Press, New York, USA. pp. 283.

15. Janny L., Ménézo Y.J. Maternal age effect on early human embryonic development and blastocyst formation. Mol. Reprod. Dev. 1996; 45: 31

16. Tesarik J. Developmental failure during the preimplantation period of human embryogenesis. En Van Blerkom J. (Edit). The Biological Basis of early human reproductive failure. Oxforf University Press. New York, USA. pp. 327-344.

17. Leese HJ. Formation and function of oviduct fluid. J. Reprod. Fertil 1988; 82: 843 .

18. Telford NA., Watson AJ., Schultz GA. Transition from maternal to embryonic control in early mamalian development: a comparison of several species. Mol. Reprod. Dev. 1990; 26: 90.

19. Gardner DK., Lane M., Spitzer A., Batt PA. Enhanced rates of cleavage and development for sheep zygotes cultured to the blastocyst stage in vitro in the absence of serum and somatic cells: amino acids, vitamins and culturing embryos in groups stimulate development. Biol. Reprod. 1994; 50: 390.

20. Gardner DK., Lane M., Calderon I., Leeton I. Environment of the preimplantation human embryo in vivo: metabolite analysis of oviduct and uterine fluids and metabolism of cumulus cells. Fertil Steril 1996; 65: 349 .

21. Lane M., Gardner DK. Increase in postimplantation development of cultured mouse embryos by amino acids and induction of fetal retardation and exencephaly by ammonium ions. J. Reprod. Fertil. 1994; 102: 305.

22. Gardner DK., Leese HJ. Concentration of nutrients in mouse oviduct fluid and their effects on embryo development and metabolism in vitro. J. Reprod. Fertil. 1990; 88: 361.

23. Jones GM., Trounson AO., Gardner DK et al. Evolution of a culture protocol for successful blastocyst development and pregnancy. Hum. Reprod. 1998; 13: 169.

24. Fong CY., Bongso A., Ng S.-C et al. Ongoing normal pregnancy after transfer of zona-free blastocyst: implications for embryo transfer in the human. Hum. Reprod. 1997; 12: 557.

25. Sakkas D., Shoukir Y., Chardonnens D. et al. Early clevage of human embryos to the two-cell stage after intracytoplasmic sperm injection as an indicator of embryo viability. Hum. Reprod. 1998; 13: 182. 